Original Research Paper

\title{
Toward a Good Decision to Improve the Weight of Control of Expenditure for Local Communities
}

\author{
Aanouar Riad Solh and Mourad El Belkacemi \\ Laboratoire Conception et Systèmes (Microélectronique et Informatique), \\ Faculty of Sciences Rabat, University Mohammed V-Agdal, Rabat, Morocco
}

\author{
Article history \\ Received: 16-03-2015 \\ Revised: 23-12-2015 \\ Accepted: 24-03-2016 \\ Corresponding Author: \\ Anouar Riad Solh \\ Laboratoire Conception et \\ Systèmes (Microélectronique et \\ Informatique), Faculty of \\ Sciences Rabat, University \\ Mohammed V-Agdal, Rabat, \\ Morocco \\ Email: anouarriadsolh@yahoo.fr
}

\begin{abstract}
In order to improve the weight control of local government spending, we have developed a technique to supervise the classification of local authorities according to their expense ratios. This aims to develop the repository of rules and decision-making skills of business leaders of local communities and enabling to detect frauds in expenditure ratios that cause weakness of the Current Flow margin (CCF).
\end{abstract}

Keywords: Datamining, Unsupervised Classification, Supervised Classification, Decision Tree, Knowledge, Clustering Algorithms, Separation Distance, Categorical Data

\section{Introduction}

Projections of future finance laws require a reflection on the sustainability of public finances face a continuing global economic crisis. Decisions are already taken by several countries on fiscal austerity and fiscal consolidation, to reduce deficits and debt levels of countries. However, expenditure rationalization will be effective at the national level that when established at the regional level (MDFEDLP, 2004; Riad Solh and El Belkacemi, 2015).

As part of the optimization of expenses of CL, we have developed a new classification technique to compare communities according to control their expenditure on the basis of current cash flow (MAC) (MDFEDLP, 2004; Riad Solh and El Belkacemi, 2015).

But the comparison of communities according to their MAC values is relative and does not produce reliable results for financial analysts because of the diversity of their ways and their revenue ratios. It why we introduce segmentation techniques to group communities that share the same levels of revenue ratios (MDFEDLP, 2004; Riad Solh and El Belkacemi, 2015).

For each community, we measured the distance between the value of the CCF and the value of the largest CCF cluster to which it belongs.

Depending on the value of this distance, we can determine the classification of this community in the cluster to inform about its weight-control spending.
Indeed, a short distance is a significant weight and a significant distance results in a low weight (MDFEDLP, 2004; Riad Solh and El Belkacemi, 2015).

In order to improve the weight control spending of the LCs and to weaken the distance between its CCF and the highest $\mathrm{CCF}$ of its cluster (center of gravity of the cluster), we used techniques of supervised classification of CCF values of communities according to their expense ratios. This aims to develop the repository of rules and decision-making skills of business leaders of local communities and enabling the detect frauds in expenditure ratios that cause weakness of the margin of current flow.

On the basis of those techniques, we can deduce the measures to be applied at the expense ratios of the community to increase its $\mathrm{CCF}$ and minimize the distance between the $\mathrm{CCF}$ and the center of gravity of the cluster.

\section{The Limits of the Basic Classification}

In order to standardize and categorize the value of the $C C F$, we defined for each community $L C_{i}$ the following report of its $C C F$ categorization (Riad Solh and El Belkacemi, 2015) (NCCF):

$$
\operatorname{NCCF}\left(L C_{i}\right)=\frac{C C F\left(L C_{i}\right)}{\operatorname{MAX}(C C F)}
$$


where, $C C F\left(L C_{i}\right)$ is the $C C F$ value of community $L C_{i}$ and $M A X(C C F)$ is the maximum value of CCF same types of communities.

This ratio which is less than or equal to '1', tells us about the CCF value of $L C_{i}$ over most CCF communities of the same type (Riad Solh and El Belkacemi, 2015). For example:

- $\mathrm{CCF}(\mathrm{PR} 6)=32715 \mathrm{MMDH}$

- $\operatorname{MAX}(\mathrm{CCF})=\mathrm{CCF}(\mathrm{PR} 13)=71185 \mathrm{MMDH}$

- $\quad \mathrm{NCCF}(\mathrm{PR} 6)=\mathrm{CCF}(\mathrm{PR} 6) / \mathrm{MAX}(\mathrm{CCF})$

- $\quad \mathrm{NCCF}(\mathrm{PR} 6)=32715 \mathrm{MMDH} / 71185 \mathrm{MMDH}$

- $\quad \mathrm{NCCF}(\mathrm{PR} 6)=0,460$

- $\mathrm{NCCF}(\mathrm{PR} 13)=\mathrm{CCF}(\mathrm{PR} 13) / \mathrm{CCF}(\mathrm{PR} 13)=1$

To make the correspondence between the NCCF report and the weight of expenditure control (category CCF (Table 1)) (Chang and Ding, 2005; Solh and
El Belkacemi, 2015; Hanumantha et al., 2011), we proposed the following categorization.

The more the CCF report categorization (NCCF) is closed to ' 1 ', better is the weight-control spending and vice versa (Riad Solh and El Belkacemi, 2015).

The result of the traditional classification of 16 provinces (previous example) according to CCF allows developing the following (Table 2).

So it is clear that this classification has deficiencies and weaknesses due to the different levels of revenue ratios (Riad Solh and El Belkacemi, 2015).

The classification will be relevant when the LC have the same means and the same reference point. That is why we introduce a segmentation technique (Sivaram and Ramar, 2010; Antonellis et al., 2007; Riad Solh and El Belkacemi, 2015) to group and classify LC who share the same level of revenue ratios (Fig. 1).

Table 1. Correspondence between the NCCF report and the category of the CCF (Riad Solh and El Belkacemi, 2015)

\begin{tabular}{lllll}
\hline Indicator & Operator & Margin & Category CCF & Situation of control spending \\
\hline NCCF & $<$ & 0 & Category 6 & Critical state \\
& In & {$[0,0.2]$} & Category 5 & very low \\
& In & {$[0.2,0.4]$} & Category 4 & Low \\
& In & {$[0.4,0.6]$} & Category 3 & Average \\
& In & {$[0.6,0.8]$} & Category 2 & Well \\
& $>=$ & 0.8 & Category 1 & Very well \\
\hline
\end{tabular}

Table 2. The result of the traditional classification of 16 provinces (Riad Solh and El Belkacemi, 2015)

\begin{tabular}{|c|c|c|c|}
\hline $\mathrm{LC}$ & NCCF & Category CCF & Situation of control spending \\
\hline PR 10 & {$[0,0.2]$} & Category 5 & Very low \\
\hline PR 7 & {$[0,0.2]$} & Category 5 & Very low \\
\hline PR 15 & {$[0.2,0.4]$} & Category 4 & Low \\
\hline PR 1 & {$[0.2,0.4]$} & Category 4 & Low \\
\hline PR 11 & {$[0.2,0.4]$} & Category 4 & Low \\
\hline PR 14 & {$[0.2,0.4]$} & Category 4 & Low \\
\hline PR 5 & {$[0.4,0.6]$} & Category 3 & Average \\
\hline PR 16 & {$[0.4,0.6]$} & Category 3 & Average \\
\hline PR 6 & {$[0.4,0.6]$} & Category 3 & Average \\
\hline PR 2 & {$[0.4,0.6]$} & Category 3 & Average \\
\hline PR 4 & {$[0.4,0.6]$} & Category 3 & Average \\
\hline PR 3 & {$[0.4,0.6]$} & Category 3 & Average \\
\hline PR 12 & {$[0.4,0.6]$} & Category 3 & Average \\
\hline PR 9 & {$[0.4,0.6]$} & Category 2 & Well \\
\hline PR 8 & {$[0.8,1]$} & Category 1 & Very well \\
\hline PR 13 & {$[0.8,1]$} & Category 1 & Very well \\
\hline
\end{tabular}

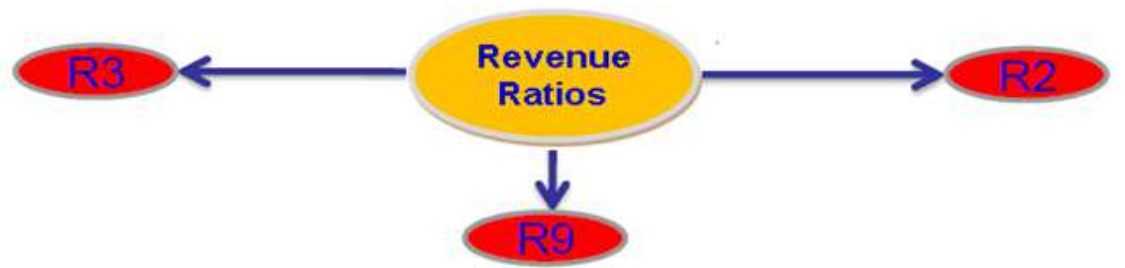

Ratios de Recettes: $\left\{\begin{array}{l}\text { R2: The share of VAT in the revenue. } \\ \text { R3: The share of the taxation in the receipts. } \\ \text { R9: Rate of saving rough. }\end{array}\right.$

Fig. 1. Revenue ratios 


\section{Setting the Points of Reference and Ensuring a Relevant Classification of LC According to their Means}

In order to make a relevant and accurate classification, we segmented first the LC (Sivaram and Ramar, 2010; Antonellis et al., 2007; Riad Solh and El Belkacemi, 2015) according to their local revenue ratios (MDFEDLP, 2004; Riad Solh and El Belkacemi, 2015) by producing a set of clusters (Shih et al., 2010; Ayesha et al., 2010; Ivancsy and Kovacs, 2006; Riad Solh and El Belkacemi, 2015) (Fig. 2).

As a result, for each community, we measured the distance between the value of the CCF and the value of the largest CCF cluster to which it belongs (Sarangi and Murthy, 2010; Holmes, 2005; Riad Solh and El Belkacemi, 2015) (Fig. 3).
At the cluster level ' $\mathrm{C}_{1}$ ', the community $\mathrm{LC}_{1}$ has the largest $\mathrm{CCF}$ which is ' $\mathrm{CCF}_{1}$ '.

Dist $_{\mathrm{k}}\left(\mathrm{C}_{1}\right)$ : It's the distance between the CCF community $\mathrm{LC}_{\mathrm{k}}$ of cluster $\mathrm{C}_{1}{ }^{\prime} \mathrm{CCF}_{\mathrm{k}}\left(\mathrm{C}_{1}\right)$ ' and the highest $\mathrm{CCF}$ ' $\mathrm{CCF}_{1}\left(\mathrm{C}_{1}\right)$ ' of cluster $\mathrm{C}_{1}$.

What are the precautions to be taken by the manager of CL tops to achieve the best of its category CCF cluster?

Secondly, we classified (supervised classification) (Hanumantha et al., 2011; Adeyemo and Kuye, 2006) CCF Communities according to their expense ratios from (Fig. 4) (Riad Solh and El Belkacemi, 2015): Financial autonomy, the share of expenses in spending the weight of debt service in operating expenses and the rate of indebtedness (Fig. 7).

The following chart describes the layout of NCCF for a sample of 16 provinces (previous example) in relation to their expense ratios for 2002 (Fig. 5).

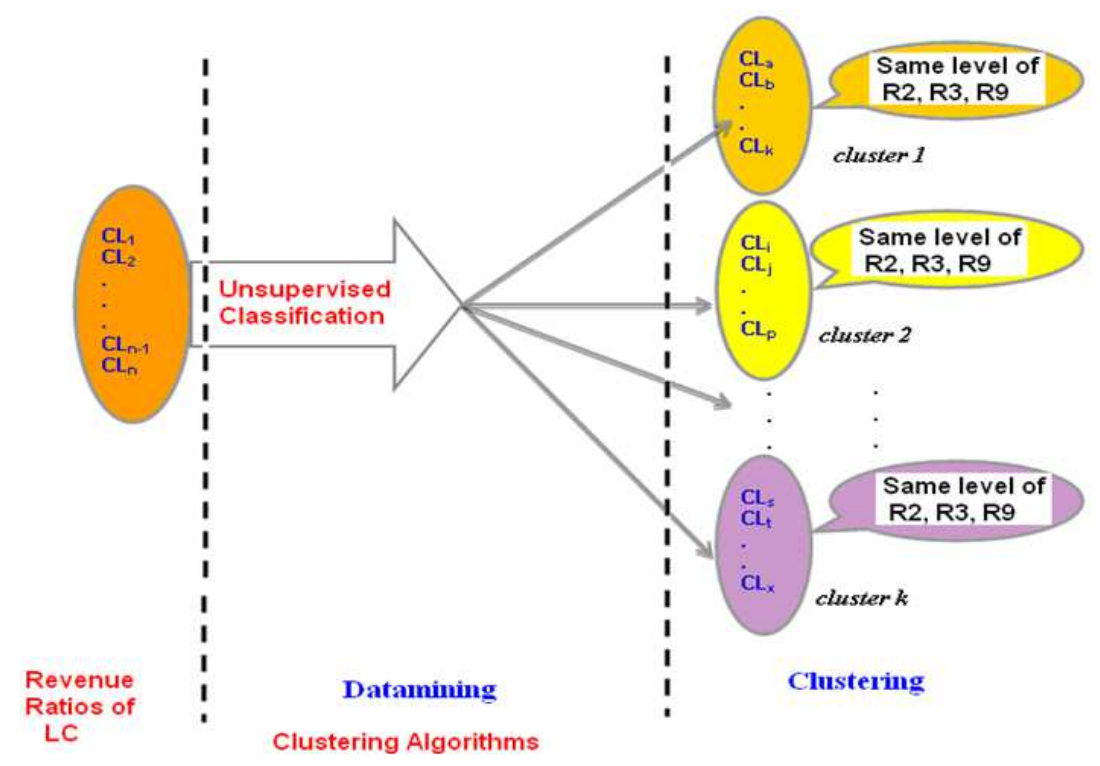

Fig. 2. Segmentation of $\mathrm{LC}$ according to their revenue ratios by clustering algorithms

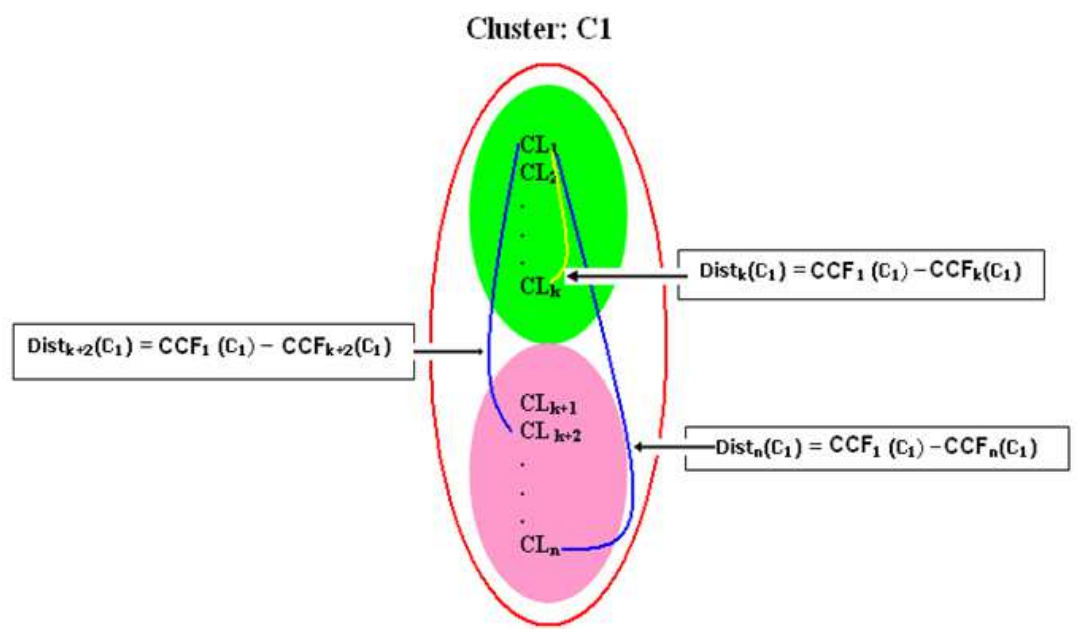

Fig. 3. Calculating distances in a cluster 


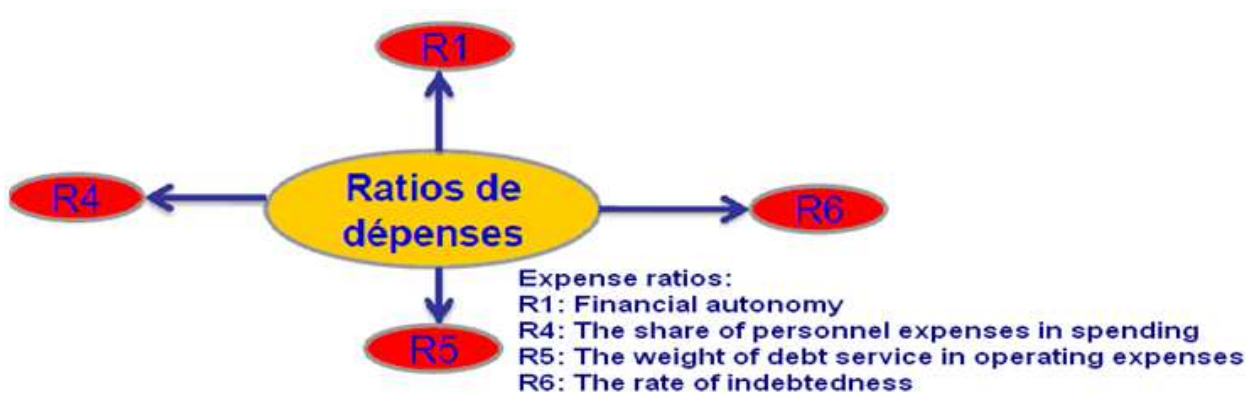

Fig. 4. Expense ratios

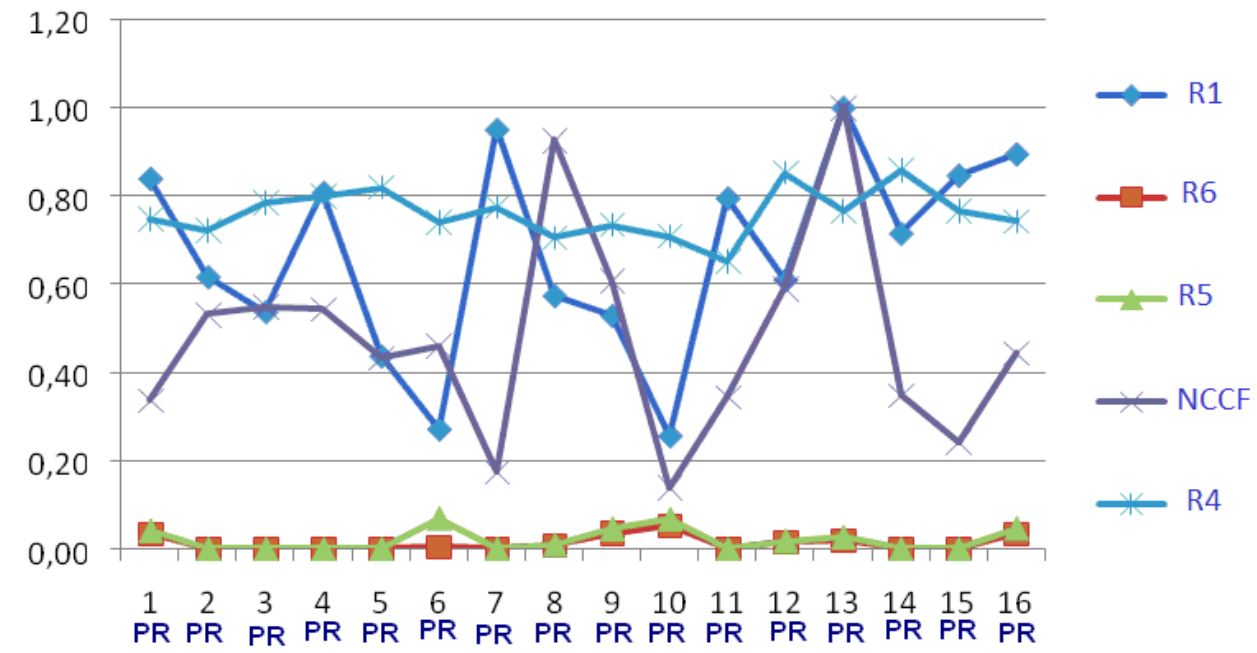

Fig. 5. Knowledge generation by type of CCF and depending on expense ratios

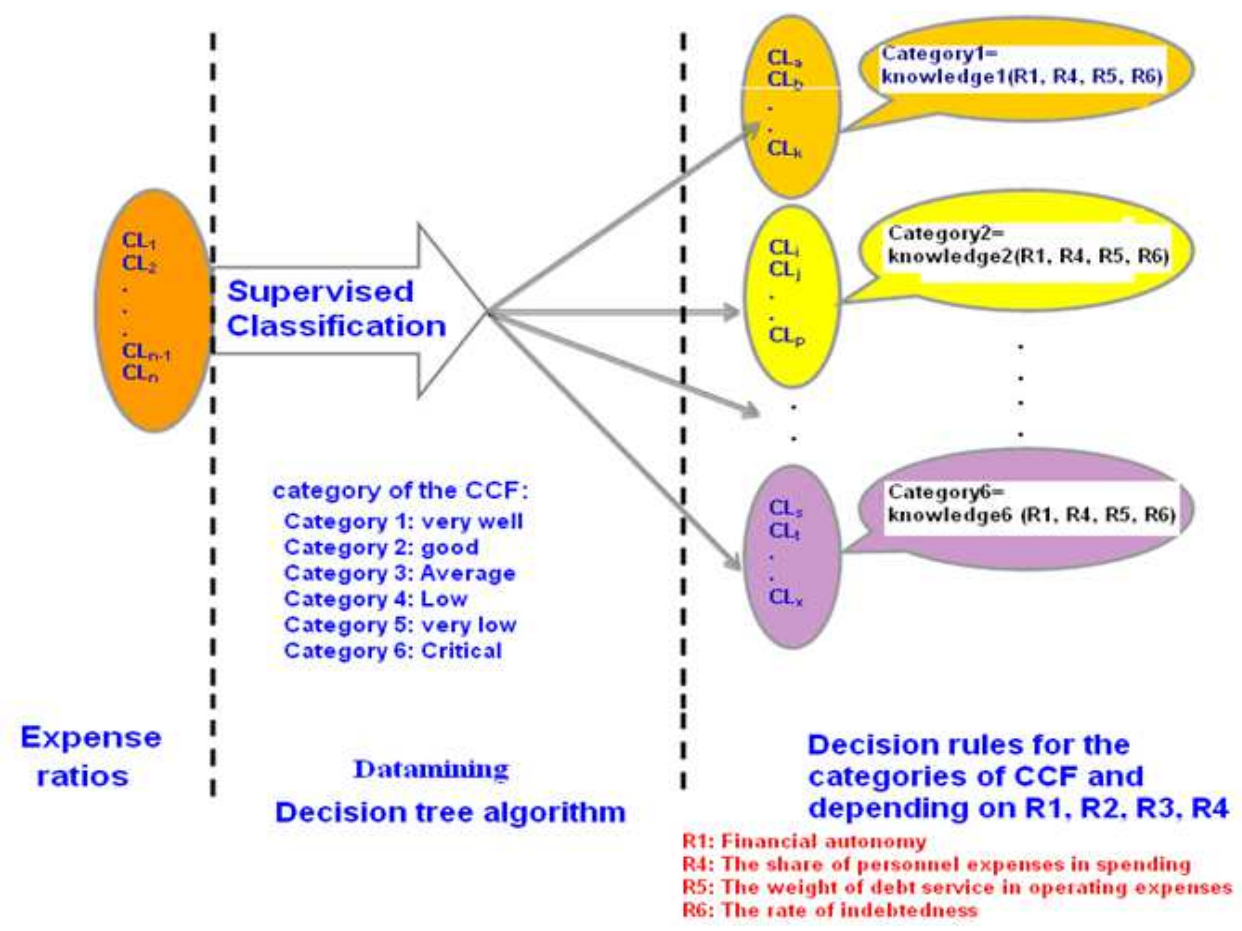

Fig. 6. Knowledge generation by type of CCF and depending on expense ratios 
Our objective is to generate knowledge and decision rules (Adeyemo and Kuye, 2006; Anyanwu and Shiva, 2013; Vasantha and Bharathy, 2010; Hall and Holmes, 2003; Ganesh and Chandrasekar, 2011) type of CCF (Fig. 6).

According to this knowledge, the manager of a CL tops may have a look on the values of expense ratios (MDFEDLP, 2004; Riad Solh and El Belkacemi, 2015) in order to reduce the distance between the CCF and the best CCF of its cluster.

Result: Evolution of the grade level of CCF in the same cluster.

\section{Description of the Method}

The procedure of the clustering of communities is discussed in our article reference (Riad Solh and El Belkacemi, 2015; Hee-Jung and Kim, 2009)

\section{Improving the Weight-Control Spending}

We try to classify CLs according to their CCF based on their expense ratios (MDFEDLP, 2004; Riad Solh and El Belkacemi, 2015). For this, we use decision tree algorithms (Anyanwu and Shiva, 2013; Vasantha and Bharathy, 2010; Hall and Holmes, 2003; Ganesh and Chandrasekar, 2011) to develop the repository of rules and decision-making skills.

Based on these standards, we can deduce the measures to be implemented at the expense ratios for the leaders of a CL to increase the level of CCF (moving from a lower to a higher level in its class of CCF level).

Let $n$ be the number of communities in the cluster $\left(\mathrm{C}_{\mathrm{c}}\right)$ that has $\mathrm{k}$ categories (CAT) of $\mathrm{CCF}$ with $\mathrm{k}<=6$.

We note that the best CCF of a cluster is its center of gravity.

The concern of the leader of a CL is how to converge its class CCF to that of the center of gravity of the cluster, chasing all communities in a cluster share the same level of revenue ratios.

In our case, the community with the best CCF in a cluster ensures good control and rationalization of expenditures over revenues.

For each category $\mathrm{i}$ of $\mathrm{CCF}$ we generate the decisional knowledge (Anyanwu and Shiva, 2013; Vasantha and Bharathy, 2010; Hall and Holmes, 2003; Ganesh and Chandrasekar, 2011) adequately according to their expense ratios by decision trees algorithms (data mining algorithms).

Thus, Knowledge (i) on the category (i) is based on expense ratios R1, R4, R5, R6, etc (Fig. 7).

CCF category desired by the leaders of a local authority is that of the center of gravity of the cluster. To ensure good control of expenses and to have that desired CCF type, we must respect the decision rules for its knowledge (Anyanwu and Shiva, 2013; Vasantha and Bharathy, 2010; Hall and Holmes, 2003; Ganesh and Chandrasekar, 2011).

\section{Cluster(c)}

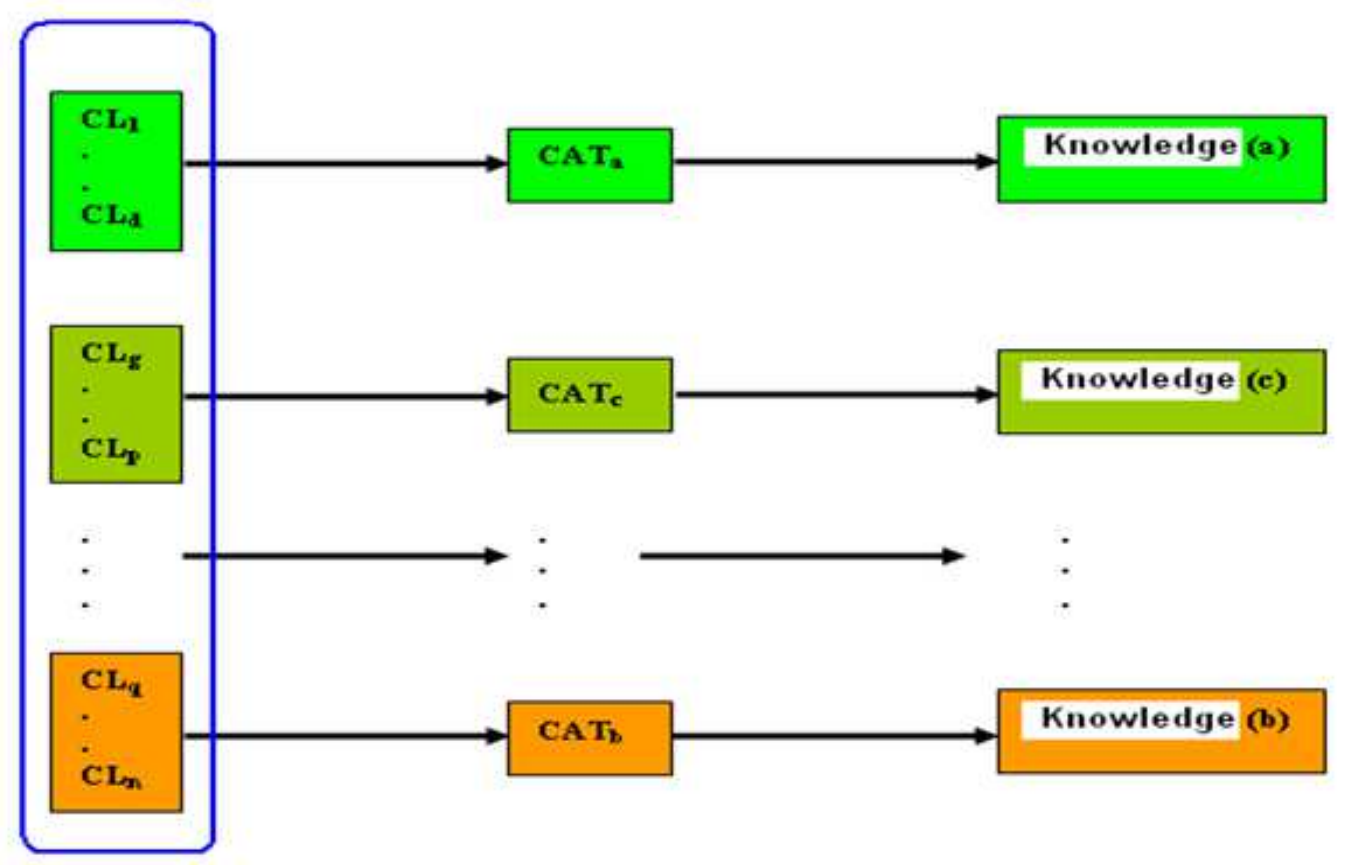

Fig. 7. Segmentation of LA by their category of CCF 


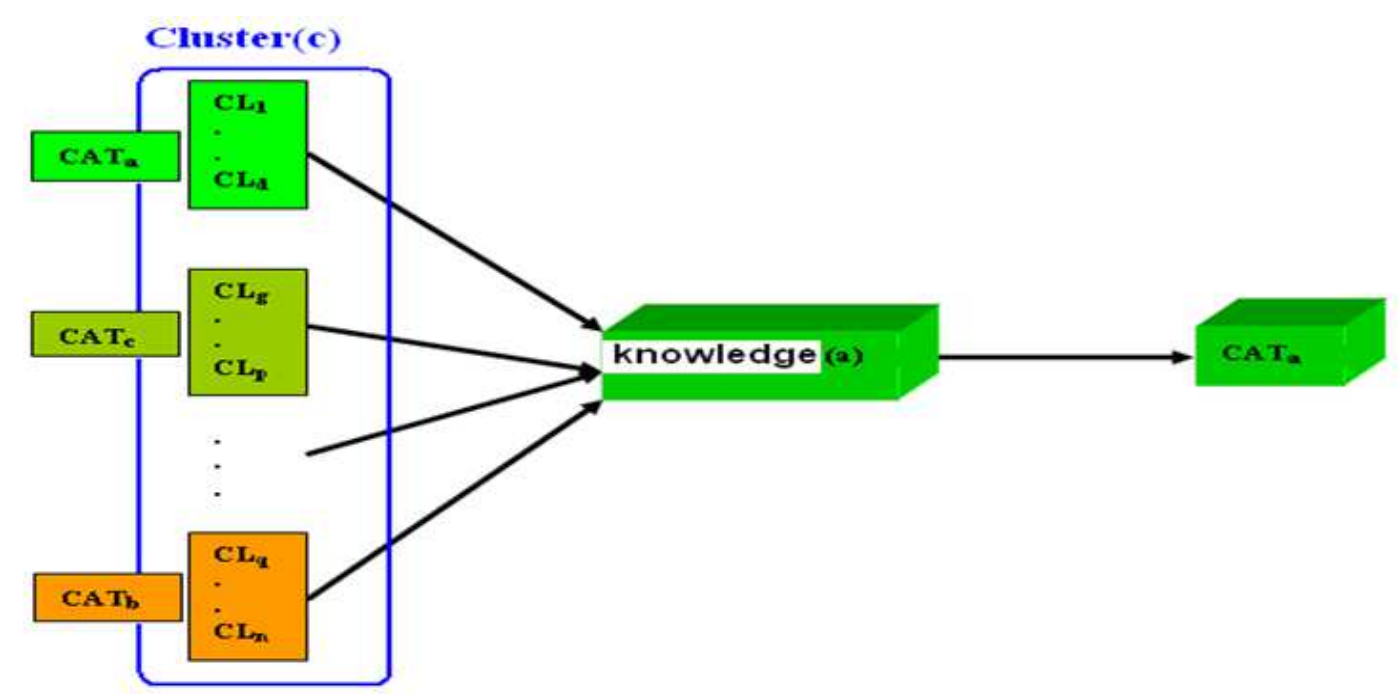

Fig. 8. Respect the knowledge: 'Knowledge (a)' returns to respect the rule R1, the rule R4, the rule R5 and R6 rule on 'Knowledge (a)'

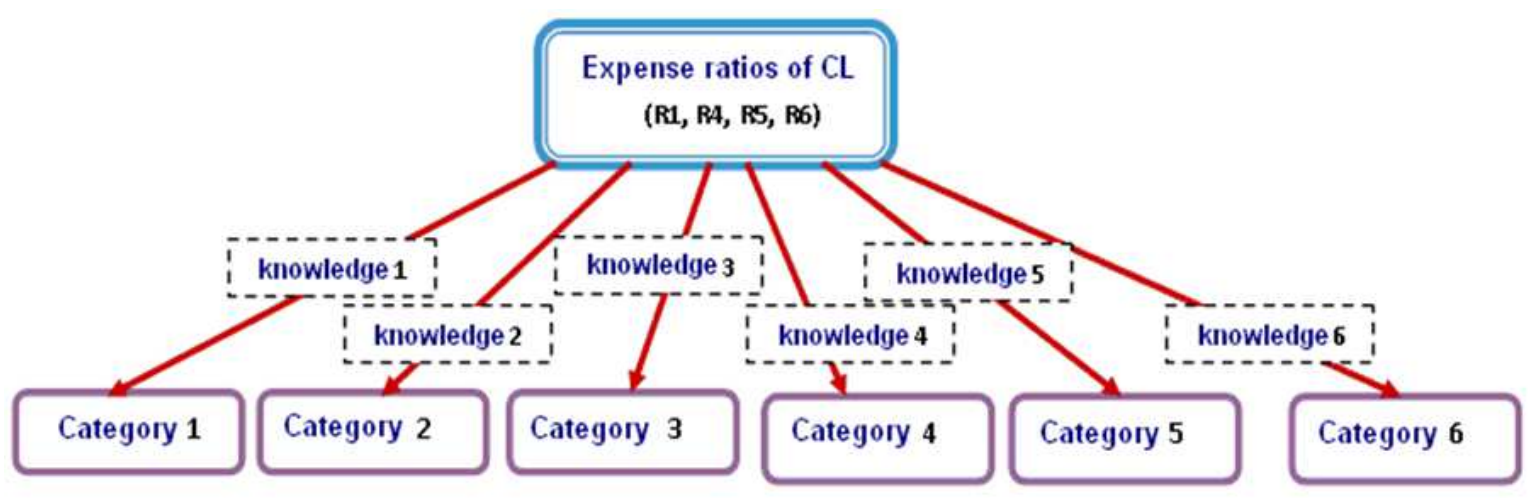

Fig. 9. The figure shows the decision tree generating categories of CCF according to local government spending ratios

If we assume that the class of CCF: ' $\mathrm{CAT}_{\mathrm{a}}$ ' is the best class of the cluster, the local community leaders in the cluster must meet the knowledge on this class of CCF: 'Knowledge (a)' to ensure good rationalization and tight control of expenses.

Respect the knowledge: 'Knowledge (a)' returns to respect the rule $\mathrm{R} 1$, the rule $\mathrm{R} 4$, the rule $\mathrm{R} 5$ and $\mathrm{R} 6$ rule on 'Knowledge (a)' with (Fig. 8):

- R1: Financial autonomy

- R4: The share of staff expenses in spending

- R5: The weight of debt service in operating expenses

- R6: The rate of indebtedness

List of knowledge (Fig. 9):

- $\quad$ Category $1=$ knowledge1 (R1, R4, R5, R6)

- $\quad$ Category2 = knowledge2 (R1, R4, R5, R6)

- $\quad$ Category3 = knowledge3 (R1, R4, R5, R6)

- $\quad$ Category4 = knowledge4 (R1, R4, R5, R6)
- $\quad$ Category5 = knowledge5 (R1, R4, R5, R6)

- $\quad$ Category6 = knowledge6 (R1, R4, R5, R6)

\section{Evolution of CCF'S Category of a Local Community}

The evolution of the CL MAC category is explained at our article reference (Riad Solh and El Belkacemi, 2015).

The more the CCF category of a community is away from the center of gravity of the cluster, the more streamlined procedure applied by these leaders will be rigorous.

\section{Some Results}

The following Fig. 10 shows the necessary changes in the categories of the CCF for a sample of 16 provinces (LC) in order to ensure the rationalization of expenditures based on the (tow-step algorithm) segmentation of their financial data (revenue ratios and CCF) for 2002. 


\begin{tabular}{|c|c|c|c|c|c|c|}
\hline LC & category & category2 & category3 & category4 & category5 & category6 \\
\hline PR1 & & & & $\mathrm{X}$ & & \\
\hline PR2 & & & $\mathrm{X}$ & & & \\
\hline PR3 & $\mathrm{Y}$ & & $\mathrm{Z}$ & & & \\
\hline PR4 & & & $\mathrm{X}$ & & & \\
\hline PR5 & & $\mathrm{Y}$ & $\mathrm{Z}$ & & & \\
\hline PR6 & & & $\mathrm{X}$ & & & \\
\hline PR7 & & $\mathrm{Y}$ & & & $\mathrm{Z}$ & \\
\hline PR8 & $\mathrm{X}$ & & & & & \\
\hline PR9 & & $\mathrm{X}$ & & & & \\
\hline PR10 & & & $\mathrm{Y}$ & & $\mathrm{Z}$ & \\
\hline PR11 & & & & $\mathrm{X}$ & & \\
\hline PR12 & & $\mathrm{Y}$ & $\mathrm{Z}$ & & & \\
\hline PR13 & $\mathrm{X}$ & & & & & \\
\hline PR14 & $\mathrm{Y}$ & & & $\mathrm{Z}$ & & \\
\hline PR15 & & & & $\mathrm{X}$ & & \\
\hline PR16 & $\mathrm{Y}$ & & & & & \\
\hline
\end{tabular}

Fig. 10. X: The community belongs to the same category of CCF that the center of gravity of the cluster (balanced management of expenses over revenue); Z: Given these recipes, the community is poorly placed in this category because of the mismanagement of expenses over revenue; Y: Given these recipes, the community needs this type of CCF to avoid difficult financial and critical situations and to ensure proper rationalization of spending (the category of the center of gravity of the cluster where it belongs)

It is based on the decision tree algorithm (C\&RT Algorithms) to develop rules to apply in order to have the desired Category CCF.

\section{For the Community PR10:}

- The weight-control spending of the community PR10 is very low 'Category 5 ', however, the center of gravity of the cluster has a weight average expense control (Category 3)

- For the weight-control spending means, the community PR10 must respect the decision knowledge on the category of the center of gravity of the cluster 'Category 3'

- Respect the knowledge on the 'Category 3' returns to respect the R1, R4, R5 and R6 on that 'knowledge 3'

\section{The Ratios Unmanaged by the Community PR10:}

- Financial autonomy $(\mathrm{R} 1=0.022290)$ is very low due to the increase in operating expenses compared to specific recipes, it must be at least greater than the value 0.023618

- The weight of debt service in operating expenses and the rate of indebtedness are very high (annuities related to expenses and operating revenues are high) so that the average of these two ratios should not exceed the 0.039497 value (the value of its average equal 0.059349)

\section{Ratios Controlled by the Community PR10}

The ratio on the part of staff expenses in operating expenses is controllable by this community, its value: 0.707374 , normally it can go up to the value 0.852094 . So, during this period, the CL PR10 can ensure premiums for its staff or proceed to a new recruitment.

\section{Conclusion}

Rationalization of local government spending is a major project that requires goodwill of the government and the use of new technologies by adopting appropriate algorithms to develop strategic dashboards and alerts. That is why we tried to develop this decision support system that carries business assistance to community leaders to avoid difficult financial situations and to ensure good governance as a result of their spending.

This publication has a dual purpose: First, we proposed a new approach that presents an objective classification of local authorities by controlling their spending over their means. Secondly, the development of a knowledge repository, which allows the deduction of measures to be implemented at the expense ratios by 
community leaders to improve their rankings and the level of control of their expenses.

\section{Acknowledgement}

The corresponding author would like to provide his thanks to Faculty of Sciences Rabat, University Mohammed V-Agdal.

\section{Funding Information}

There are no funders of this manuscript, it is all the authors work and he did not get any funds from anyone.

\section{Author's Contributions}

Anouar Riad Solh: Participated in all experiments, coordinated the data-analysis and contributed to the writing of the manuscript.

Mourad El Belkacemi: Participated in all experiments, coordinated the data-analysis and contributed to the writing of the manuscript.

\section{Ethics}

No ethical conflicts will arise after publication of the manuscript.

\section{References}

Adeyemo, A.B. and G. Kuye, 2006. Mining students' academic performance using decision tree algorithms. J. Inform. Technol. Impact, 6: 161-170.

Antonellis, P., C. Makris and N. Tsirakis, 2007. Algorithms for clustering clickstream data. Inform. Proc. Lett., 109: 381-385. DOI: $10.1016 /$ j.ipl.2008.12.011

Anyanwu, M.N. and S.G. Shiva, 2013. Comparative analysis of serial decision tree classification algorithms. Int. J. Comput. Sci. Security, 3: 230-240.

Ayesha, S., T. Mustafa, A.R. Sattar and M.I. Khan, 2010. Data mining model for higher education system. Eur. J. Scientific Res., 43: 24-29.

Chang, C.H. and Z.K. Ding, 2005. Categorical data visualization and clustering using subjective factors. Data Knowl. Eng., 53: 243-262.

DOI: $10.1016 /$ j.datak.2004.09.001

Ganesh, S.H. and D.C. Chandrasekar, 2011. HARIALGM: Knowledge discovery and data mining in pedagogy with DNA finger printing. Int. J. Compt. Sci. Inform. Technol., 2: 1470-1473.
Hall, M.A. and G.R. Holmes, 2003. Benchmarking attribute selection techniques for discrete class data mining. IEEE Trans. Knowl. Data Eng., 15: 1437-1447. DOI: 10.1109/TKDE.2003.1245283

Hanumantha, G., Rao, G. Narender, T. Balaji and Y. Anitha, 2011. Representative based method of categorical data clustering. Int. J. Adv. Eng. Sci. Technol., 2: 152-156.

Hee-Jung, D. and J.Y. Kim, 2009. Clustering categorical data based on combinations of attribute values. Int. J. Innovative Comput. Inform. Control, 5: 4393-4405.

Holmes, F., 2005. Comparison of distance measures in cluster analysis with dichotomous data. J. Data Sci., 3: 85-100.

Ivancsy, R. and F. Kovacs, 2006. Clustering techniques utilized in web usage mining. Proceedings of the 5 th WSEAS International Conference on Artificial Intelligence, Knowledge Engineering and Data Bases, (EDB' 06), Stevens Point, Wisconsin, USA, pp: 237-242.

MDFEDLP, 2004. Guide to financial analysis of the local communities-retrospective approach. MDFEDLP.

Riad Solh, A. and M. El Belkacemi, 2015. Identification and classification of the best communities that ensure the mastery of their expenditure by using the threshold of their cluster. Modern Applied Sci., 9: 284-283. DOI: $10.5539 /$ mas.v9n4p284

Sarangi, S.R. and K. Murthy, 2010. DUST: A generalized notion of similarity between uncertain time series. Proceedings of the 16th ACM SIGKDD International Conference on Knowledge Discovery and Data Mining, Jul. 25-28, ACM, New York, pp: 383-392. DOI: 10.1145/1835804.1835854

Shih, M.Y., J.W. Jheng and L.F. Lai, 2010. A two-step method for clustering mixed categroical and numeric dat. Tamkang J. Sci. Eng., 13: 11-19.

Sivaram, N. and K. Ramar, 2010. Applicability of clustering and classification algorithms for recruitment data mining. Int. J. Comput. Applic., 4: 23-28.

Vasantha, M. and V.S. Bharathy, 2010. Evaluation of attribute selection methods with tree based supervised classification-a case study with mammogram images. Int. J. Comput. Applic., 8: 35-38. 